\title{
Best band combination for landslide studies in temperate environments
}

\begin{abstract}
Multi-spectral imagery has great potential for the detection and delineation of landslides in temperate areas due to its ability to show changes in surface material properties. In this study, an assessment of the best band combination of the eleven-band Airborne Thematic Mapper (ATM) imagery for landslide studies was undertaken. The ATM composite image for Stonebarrow Hill in West Dorset, an area that is renowned for landslide activity, was assessed by comparing the image with a 1: 2000-scale geomorphological map compiled through ground mapping. A suggestion of the best band combination to be used under various conditions, such as in arable and pasture lands, heavily vegetated areas and shadow affected areas, is presented.
\end{abstract}

Keyword: Atmospheric temperature, Geomorphology, Imaging techniques, Landslides, Mapping, Multispectral scanners 